\title{
Numerical Modelling Analysis of Angle Bracket Connections Used in Cross Laminated Timber Constructions
}

\author{
Saeed Rezvani ${ }^{1}$ and Lina Zhou $^{2}$ \\ ${ }^{1}$ MSc student, Department of Civil Engineering, University of Victoria \\ ${ }^{2}$ Assistant Professor, Department of Civil Engineering, University of Victoria \\ *Corresponding author's e-mail: rezvani.s.saeed@gmail.com
}

\begin{abstract}
Connections are arguably one of the most critical components controlling the structural performance and failure modes of mass timber structures. Over the last two decades, demands for stronger and energy dissipative connections have been raised with increased application of mass timber products in larger and taller buildings. This paper presents numerical analyses of novel mass timber connections used in cross laminated timber structures. The connections are developed by MyTiCon with BB Stanz- und Umformtechnik GmbH angle bracket. Despite being relatively thin, these angle brackets could show comparable load resistance with thicker ones due to the reinforced web and folded edges. The commercially available finite element software ABAQUS was used to develop three dimensional (3D) numerical models to simulate the performance of angle bracket connections under different load combinations. The modelling analysis involves two phases: (1) to determine the most efficient fastener type and setup for the angle brackets connected to CLT wall and floor panels, and (2) to evaluate the capacity of angle brackets connected to CLT wall and floor panels in various loading scenarios. The findings of this study provide an insight into the behaviour of this new angle bracket connections and will be used in the design of the experimental tests in the next phase.
\end{abstract}

\section{KEYWORDS}

Cross laminated timber structures; Angle bracket connections; 3D numerical modelling

\section{INTRODUCTION}

The development of new wood products [e.g. cross laminated timber (CLT) panels] and construction technologies over the past few decades has made timber structures a viable alternative to reinforced concrete and steel structures in larger and taller buildings. The demand for timber constructions is notably increasing worldwide as the growing environmental protection movement and the encouragement of using renewable and sustainable materials in constructions (AIA, 2016; Connolly et al., 2018). CLT is a cross-wise glued-laminated panel with exceptional in-plane strength and stiffness and dimensional stability (AIA, 2016; Mohammad et al., 2013). Application of CLT may largely eliminate the natural limitations of timber as a construction material (Wang et al. 2015). Tomasi and Smith (2014) state that CLT, like other wood products, is an ideal construction material for seismically active regions. In CLT 
structures, connections are arguably the most critical elements governing structures' behaviour and failure modes (Snow et al. 2006). Therefore, it is crucial to use connectors and fasteners that exhibit high levels of ductility to resist the wind and seismic loads (Tomasi and Smith, 2014). Timber connections with thin-walled metal parts have been gradually replacing traditional carpentry joints as the formers usually possess higher ductility, less reduction of cross section and easier in-situ implementation. Remaining sufficiently anchored during high-intensity events and the ability to deform plastically for the connectors are critical for CLT structures(Sejkot et al., 2015). Steel angle brackets (for horizontal sliding forces) and hold-downs (for vertical uplift forces) are the most common types of such connectors (Tomasi and Smith, 2014). Considerable experimental and numerical studies have been conducted on the mechanical behaviour of angle bracket and hold-down systems (Casagrande et al., 2017, 2016; Gavric et al., 2015; Pozza et al., 2018; Tamagnone et al., 2018). Experimental analyses show that both tensile and shear strength of angle brackets are considerably high. (Casagrande et al., 2016; D'Arenzo et al., 2018; Flatscher et al., 2014; Gavric et al., 2015). Angle bracket connections are often loaded under multiple directions in real practice. Combination behaviours under both axial and lateral loads affect the performance of timber structures. Neglecting any one of them may lead to unrealistic design (Sejkot et al., 2015).

BB Angle Brackets, Type A90 and A105, are one-piece, non-welded, and face-fixed angle brackets newly manufactured by BB Stanz- und Umformtechnik GmbH. They are used by MyTiCon for a new CLT angle bracket connection. These brackets are made of pre-galvanized steel S $250 \mathrm{GD}+\mathrm{Z} 275$, and each type is available with or without an embossed rib. The design details of BB Type A105 angle bracket and the Abaqus model are shown in Figure 1. The reinforcement designed at the right angle of the brackets contributes most to the stiffness and strength (ETA, 2018). The aim of this study is to evaluate the mechanical properties of these angle bracket connections under different loading scenarios via Finite Element Analysis (FEA).

(a)

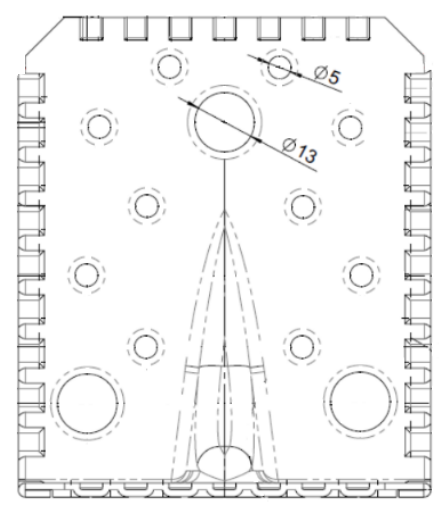

(b)

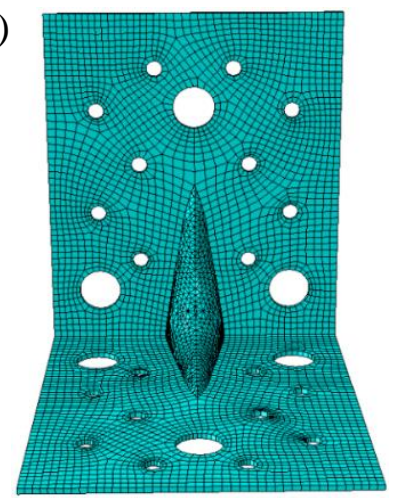

Figure 1. BB Type A105 angle bracket: (a) Details, (b) Abaqus model.

\section{METHODOLOGY}

Numerical modelling analysis is a cheaper and faster research method compared to experimental testing, although simplification is usually required (Sejkot et al., 2015). Once these models get 
verified by experimental data, they can be used to analyze structures under combinations of different loading conditions. D'Arenzo et al. (2018) used two-node non-linear spring elements with three degrees of freedom to model the mechanical behaviour of wood to angle bracket nail/screw connections. Non-linear static analysis was performed by imposing $15 \mathrm{~mm}$ displacement along both uplift and shear directions. Sejkot et al. (2016) also evaluated the loadbearing capacities of angle brackets via numerical modelling method. In their models, wood members were considered orthotropic, angle brackets were modelled as shell elements, and fasteners were modelled as connectors with predetermined properties. Both studies confirmed the effectiveness of using the FE modelling approach.

Unlike above-mentioned studies, three dimensional (3D) elements were used in this study to model all the fasteners, as well as CLT panels and angle brackets. Hard contact and penalty friction were assigned for normal and tangential contact directions, respectively. CLT panels were modelled with equivalent-elastic isotropic material with Young's modulus E $=10 \mathrm{GPa}$ and Poisson's ratio $v=0.4$. While angle brackets and fasteners were modelled with elastic-plastic material with Young's modulus E $=200 \mathrm{GPa}$ and Poisson's ratio $v=0.3$. The yield and ultimate stresses of nails, screws and angle bracket are mentioned in Table 1. CLT panels and angle brackets were meshed using 8-node brick (C3D8) elements and wedge elements were used for the reinforcement part of angle brackets. The angle brackets studied herein are (1) BB Angle Bracket Type 105 (105 mm long flanges) and (2) BB Angle Bracket Type 90 (90 mm long flanges). Both of them have a thickness of $1.5 \mathrm{~mm}$. A pair of angle brackets were placed symmetrically at two sides of the CLT panel in each connection to prevent rotation.

Table 1. Material properties (ETA, 2018)

\begin{tabular}{ccc}
\hline Member & Yield Stress $(\mathrm{MPa})$ & Ultimate Stress $(\mathrm{MPa})$ \\
\hline Nail & 290 & 575 \\
Screw (both types) & 205 & 505 \\
Angle Bracket & 250 & 330 \\
\hline
\end{tabular}

Numerical analysis of this study consists of two parts: (1) to determine the most efficient combination of fasteners for the angle brackets, and (2) to evaluate the capacity of angle brackets connected to CLT wall and floor panels in various loading scenarios.

Part (I): Three design details of fasteners were considered in Part I for the Type 105 angle bracket connection. In the first case, the angle bracket was fastened to CLT walls and floors with $4 \times 60 \mathrm{~mm}$ nails; in the second case, it was fastened to CLT walls and floors with $4.5 \times 65 \mathrm{~mm}$ screws to reinforce the uplift resistance and in the third case, the angle bracket was fastened to CLT walls and floors with combination of $4 \times 60 \mathrm{~mm}$ nails and $12 \times 80 \mathrm{~mm}$ screws. Uplift and in-plane shear displacement were applied to all of the three types of connections up to $15 \mathrm{~mm}$ to see how the design details affect the mechanical performance of angle bracket connections.

Part (II): In the second part of this study, the load-bearing capacities of angle brackets connected to CLT walls and floors were estimated in different loading scenarios by using the most efficient fastener setup determined in Part (I). As illustrated in Figure 2, the primary loading conditions include uplift $\left(\mathrm{F}_{1}\right)$, in-plane shear $\left(\mathrm{F}_{2}\right)$ and out of plane shear $\left(\mathrm{F}_{3}\right)$. Two types of angel bracket: Type A90 and Type A105 were considered in this part. They were loaded under 
primary loads individually (i.e. $F_{1} F_{2}$, and $F_{3}$ ) and different combinations of them. (i.e. $F_{1}$ with $F_{2}$, $F_{1}$ with $F_{3}, F_{2}$ with $F_{3}$, and $F_{1}, F_{2}$ and $F_{3}$ all together). Thus, there were seven loading conditions (i.e. three primary and four combined ones) considered in the phase.
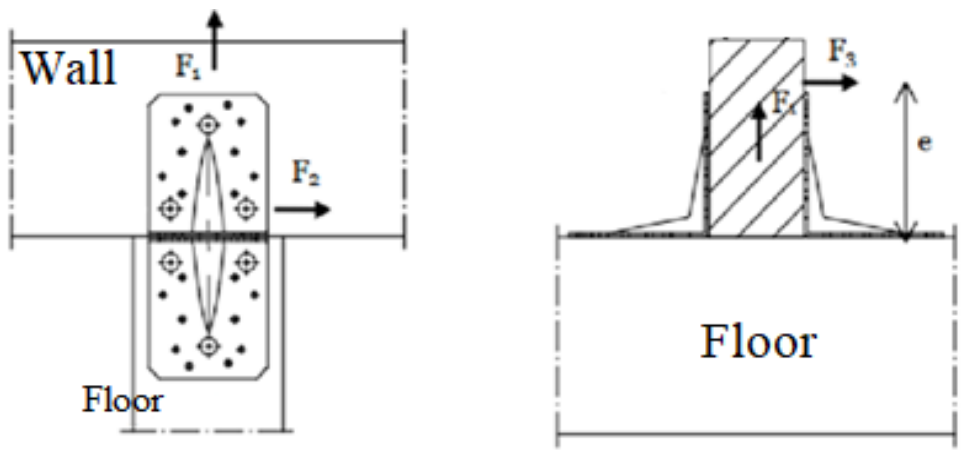

Figure 2. Details of angle bracket connections and loading directions.

\section{RESULTS AND DISCUSSION}

Figures 3 and 4 show deformed shapes of Type A105 angle bracket connections with three different fastener details under uplift and in-plane shear loads, respectively. Figure 5 illustrates the load-displacement curves of a single angle bracket connection with three fastener details under uplift and shear loads. As indicated in Figure 5 and Table 2, the effect of fastener details on the shear resistance of angle bracket connections is limited. While the combination of $4 \times 60$ $\mathrm{mm}$ nails and $12 \times 80 \mathrm{~mm}$ screws performs significantly better in uplift direction $\left(\mathrm{F}_{1}\right)$. So, the combination of $4 \times 60 \mathrm{~mm}$ nails and $12 \times 80 \mathrm{~mm}$ screws was selected for the Part II study.

(a)

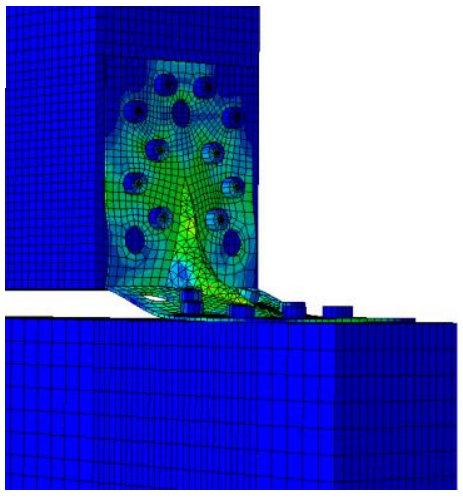

(b)

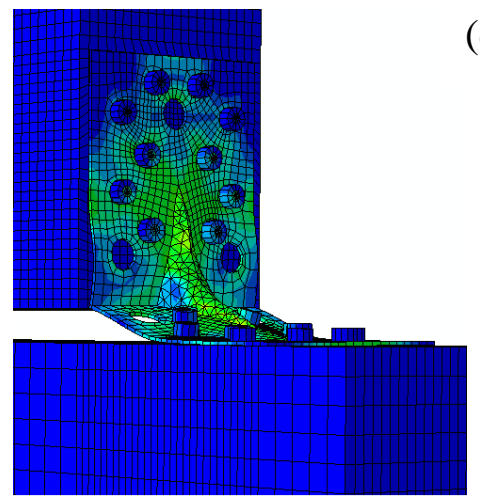

(c)

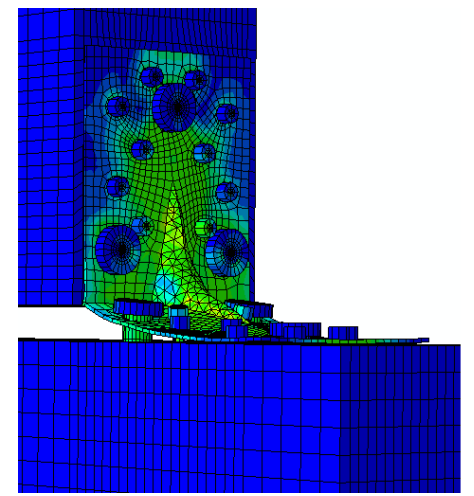

Figure 3. Deformed Type A105 connections under uplift load: (a) Only $4 \times 60 \mathrm{~mm}$ nails; (b) Only $4.5 \times 65 \mathrm{~mm}$ screws; and (c) $4 \times 60 \mathrm{~mm}$ nails and $12 \times 80 \mathrm{~mm}$ screws. 

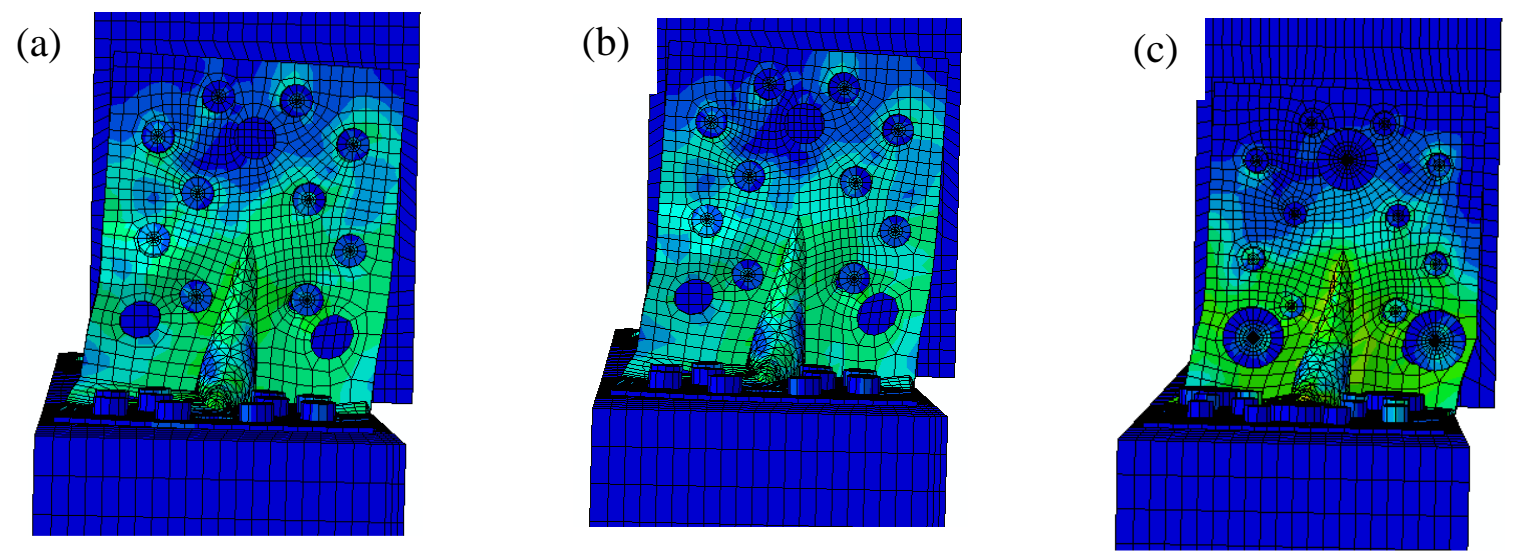

Figure 4. Deformed Type A105 connections under shear load: (a) Only $4 \times 60 \mathrm{~mm}$ nails; (b) Only $4.5 \times 65 \mathrm{~mm}$ screws; and (c) $4 \times 60 \mathrm{~mm}$ nails and $12 \times 80 \mathrm{~mm}$ screws.

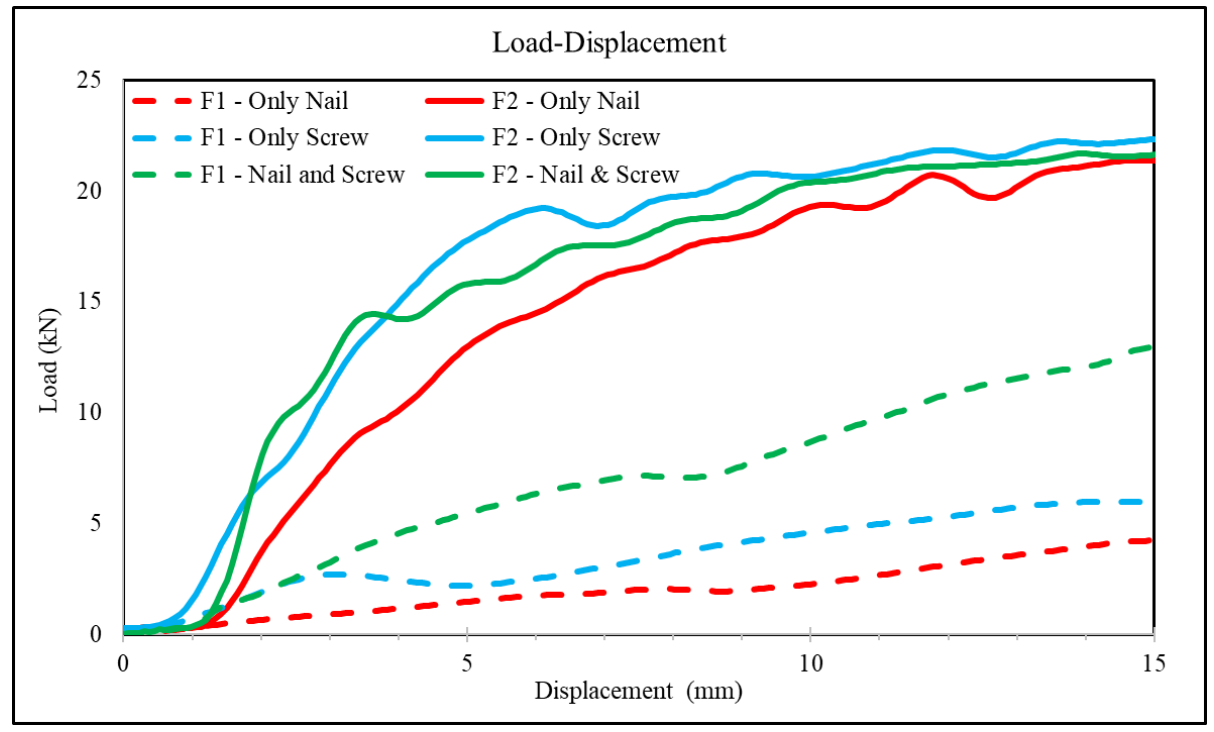

Figure 5. Load-deformation curves of singe angle bracket connection with three fastener details under $F_{1}$ (uplift) and $F_{2}$ (shear) loads.

Table 2. Load bearing capacity of angle bracket connection with three fastener details

\begin{tabular}{ccc}
\hline \multirow{2}{*}{ Fastener setup } & \multicolumn{2}{c}{ Load Bearing Capacity $(\mathrm{kN})$} \\
\cline { 2 - 3 } & Uplift $\left(\mathrm{F}_{1}\right)$ & Shear $\left(\mathrm{F}_{2}\right)$ \\
\hline Only $4 \times 60 \mathrm{~mm}$ nails & 4.2 & 21.4 \\
Only $4.5 \times 65 \mathrm{~mm}$ screws & 6.0 & 22.3 \\
Combination of $4 \times 60 \mathrm{~mm}$ nails and $12 \times 80 \mathrm{~mm}$ screws & 13.0 & 21.7 \\
\hline
\end{tabular}

Figure 6 illustrates the load-displacement curves of one direction component of a single angle bracket connection under different loading combinations. As can be seen, the connections under different loading combinations show very similar behaviour in shear when the displacement is less than around $3 \mathrm{~mm}$. When the displacement goes beyond $3 \mathrm{~mm}$, the shear resistance is reduced due to the combined loads on the other directions. The case under three combined loads 
has the smallest shear resistance. For the uplift component, the withdrawal of the fasteners governs the failure mechanisms. The uplift resistance increases under $F_{1}$ and $F_{2}$ combined loads before it reaches to $15 \mathrm{~mm}$ displacement as the additional in-plane shear reinforces the friction between the fastener and CLT panels. While the out of plane shear will reduce the uplift resistance when the displacement is less than $8 \mathrm{~mm}$. All of the curves show a slip at the beginning as the pre-drilled holes in angle brackets are larger than fastener diameters.

Table 3 shows the estimated load resistance of one angle bracket connection under one- and multi-directional loads. As can be seen, the connections have the largest shear resistance when only loaded in one direction. The smallest shear resistance happens for the case loaded in three directions simultaneously. Expect that for uplift direction $\left(F_{1}\right)$, the adding of $F_{2}$ and $F_{3}$ increases the normal compression between fastener shank and wood which results in increase of withdrawal resistance. Therefore the uplift resistance of connections is almost the same for single- and multi-loading conditions.

(a)

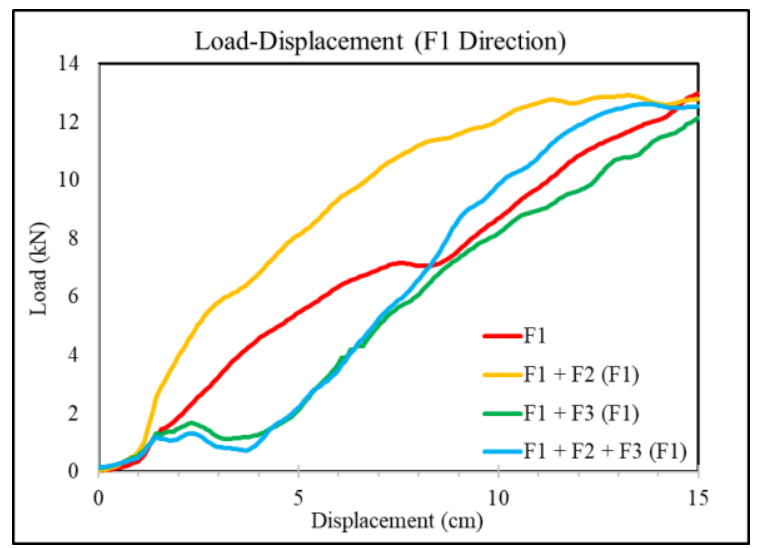

(b)

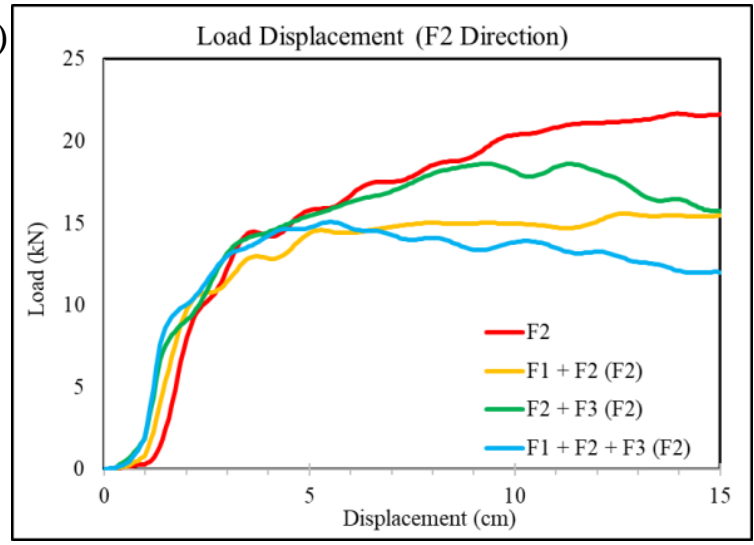

(c)

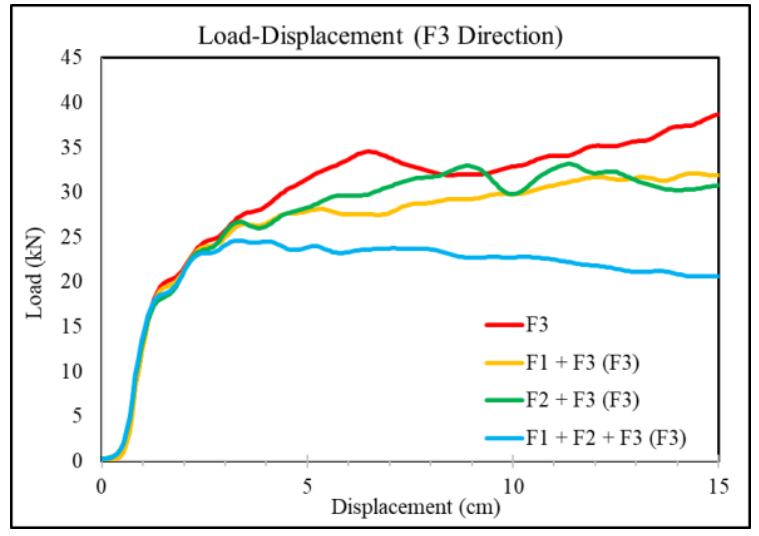

Figure 6. Load-deformation curves of Type A105 angle bracket connection under difference loading combinations: (a) Uplift component; (b) In plane shear component and (c) Out of plane shear component.

Table 3. Load bearing capacity of angle brackets under multidirectional loads

Loading

Condition
Load Bearing Capacity (kN)

$90 \mathrm{~mm}$ angle bracket

$105 \mathrm{~mm}$ angle bracket 
MOC SUMMIT / MAY 2019

\begin{tabular}{ccccccl}
\hline & $\mathrm{F}_{1}$ & $\mathrm{~F}_{2}$ & $\mathrm{~F}_{3}$ & $\mathrm{~F}_{1}$ & $\mathrm{~F}_{2}$ & \multicolumn{1}{c}{$\mathrm{F}_{3}$} \\
\hline Only $\mathrm{F}_{1}$ & 11.0 & --- & --- & 13.0 & --- & --- \\
Only $\mathrm{F}_{2}$ & --- & 17.9 & --- & --- & 21.7 & --- \\
${\text { Only } F_{3}}$ & --- & --- & 32.9 & --- & --- & 38.7 \\
$\mathrm{~F}_{1}$ with $\mathrm{F}_{2}$ & 10.5 & 11.9 & --- & 12.9 & 15.6 & --- \\
$\mathrm{F}_{1}$ with $\mathrm{F}_{3}$ & 10.1 & --- & 26.9 & 12.2 & -- & 32.1 \\
$\mathrm{~F}_{2}$ with $\mathrm{F}_{3}$ & --- & 15.7 & 28.9 & --- & 18.6 & 33.2 \\
$\mathrm{~F}_{1}, \mathrm{~F}_{2}$ and $\mathrm{F}_{3}$ & 10.0 & 13.4 & 21.2 & 12.6 & 15.1 & 24.6 \\
\hline
\end{tabular}

\section{CONCLUSION}

As the behaviour of mass timber structures is mostly controlled by connections, understanding of the performance of connections is of high importance in timber constructions. This paper presents the FE modelling analysis of two sizes of BB Angle Bracket (i.e. Type A90 and Type A105) connections under various loading conditions. The analysis consists of two stages: (1) to determine the most efficient fastener type and setup for the angle brackets connected to CLT wall and floor panels, and (2) to evaluate the capacity of angle brackets connected to CLT wall and floor panels in various loading scenarios (three unidirectional and four multidirectional scenarios). The results show that the angle bracket connections with fastener details of the combination of $4 \times 60 \mathrm{~mm}$ nails and $12 \times 80 \mathrm{~mm}$ screws have the highest uplift resistance and were used in the second stage to study the effect of loading combination on the mechanical performance of angle bracket connections. Replacing nails with screws and adding additional large size screws in the angle brackets to wood connections doesn't have a significant improvement on the shear resistance of connections. Multiple loading conditions will reduce the shear resistance capacity of connections, while there is no significant reduction on uplift resistance as the withdrawal resistance of fasteners has been reinforced due to perpendicular to shank shear deformation. This paper presents a preliminary numerical modelling study on angle bracket connections by introducing three-dimensional models for fasteners. The modelling techniques developed in this paper will be verified and improved with the experimental tests in the next phase.

\section{REFERENCES}

AIA, reThink W., 2016. Mass Timber in North America; Expanding the possibilities of wood building design 1-12.

Casagrande, D., Doudak, G., Mauro, L., Polastri, A., 2017. Analytical approach to establishing the elastic behavior of multipanel CLT shear walls subjected to lateral loads. J. Struct. Eng. 144, 4017193.

Casagrande, D., Polastri, A., Sartori, T., Loss, C., Chiodega, M., 2016. Experimental campaign for the mechanical characterization of connection systems in the seismic design of timber buildings, in: World Conference on Timber Engineering (WCTE).

Connolly, T., Loss, C., Iqbal, A., Tannert, T., 2018. Feasibility Study of Mass-Timber Cores for the UBC Tall Wood Building. Buildings 8, 98.

D’Arenzo, G., Rinaldin, G., Fossetti, M., Fragiacomo, M., 2018. Tensile and shear bahaviour of 
an innovative angle bracket for CLT structures.

ETA, E.T.A., 2018. Technical Assessment of BB A70, 90, and 105 Angle Brackets - ETA08/0183 of 2018/09/06 1-24.

Flatscher, G., Bratulic, K., Schickhofer, G., 2014. Experimental tests on cross-laminated timber joints and walls. Proc. Inst. Civ. Eng. Build. 168, 868-877.

Gavric, I., Fragiacomo, M., Ceccotti, A., 2015. Cyclic behaviour of typical metal connectors for cross-laminated (CLT) structures. Mater. Struct. 48, 1841-1857.

Mohammad, M., Douglas, B., Rammer, D., Pryor, S.E., 2013. Handbook of cross-laminated timber buildings, In: CLT handbook: cross-laminated timber/edited by Erol Karacabeyli, Brad Douglas.--US ed.; 2013; 59 p.

Pozza, L., Saetta, A., Savoia, M., Talledo, D., 2018. Angle bracket connections for CLT structures : Experimental characterization and numerical modelling. Constr. Build. Mater. 191, 95-113.

Sejkot, P., Kuklík, P., Ormarsson, S., Patlakas, P., Pošta, J., 2016. Numerical simulations of timber connections with angle brackets subjected to external loading, in: 2016 World Conference on Timber Engineering. Vienna, Austria, p. 9.

Sejkot, P., Ormarsson, S., Vessby, J., Kuklik, P., 2015. Determination of Load Bearing Capacity for Spatial Joint with Steel Angle Brackets.

Snow, M., Asiz, A., Chen, Z., Chui, Y.H., 2006. North American practices for connections in wood construction 39-48.

Tamagnone, G., Rinaldin, G., Fragiacomo, M., 2018. A novel method for non-linear design of CLT wall systems. Eng. Struct. 167, 760-771.

Tomasi, R., Smith, I., 2014. Experimental Characterization of Monotonic and Cyclic Loading Responses of CLT Panel-To-Foundation Angle Bracket Connections 1-11.

Wang, M., Song, X., Gu, X., Zhang, Y., Luo, L., 2015. Rotational Behavior of Bolted Beam-toColumn Connections with Locally Cross-Laminated Glulam. J. Struct. Eng. 141, 04014121. 